\title{
Comparison of mesh grinding and chemical washing techniques for the beneficiation of kaolins used in the white cement industry.
}

\author{
Juan Pablo Salinas Estevane a , Ma. Idalia Gómez de la Fuente ${ }^{\text {b* }}$ \\ ${ }^{a}$ Universidad Autónoma de Nuevo León (UANL), Facultad de Ciencias Químicas, Cd. Universitaria, C.P. 64570. San Nicolás de los Garza, \\ Nuevo León, México. \\ ${ }^{b}$ Universidad Autónoma de Nuevo León (UANL), Facultad de Ciencias Físico Matemática, Cd. Universitaria, C.P. 64570. San Nicolás de \\ los Garza, Nuevo León, México. \\ *e-mail: idaliagomezmx@yahoo.com.mx
}

Recibido 3 de julio de 2014, Aceptado 22 de octubre de 2014

\begin{abstract}
Kaolins are hydro aluminum silicates which are either monoclinic or triclinic in structure in accordance to their origin. Some common applications of kaolins are paper products, paints, catalyzers, white cement, etc. In the present research four different kaolins which were extracted from Villa de Reyes, S.L.P.; Mexico, were beneficiated using two different techniques: mesh grinding and chemical washing, in order to meet the requirements for the white cement industry, i.e. the mass content of $\mathrm{Fe}_{2} \mathrm{O}_{3}$ should be less than two percent of the total kaolin mass. XRD, Optical Microscopy, Colorimetry analysis were performed on the four studied kaolins. Mesh grinding and chemical washing techniques showed a similar degree of beneficiation. XRD analysis showed six different phases that make up the four different kaolins and are: saponite, kaolinite, wollastonite, stellerite, crystoballite and quartz. Most of $\mathrm{Fe}_{2} \mathrm{O}_{3}$ was located in the kaolinite, wollastonite and crystoballite phases, as could be corroborated by the combination of XRD, Optical Microscopy and Colorimetry analysis.
\end{abstract}

Keywords: ceramics, minerals, multilayer structure

\section{Introduction}

The importance of cement in our society nowadays is evident, we find it everywhere we go, from the smallest town to the biggest cities. Cement is one of the most basic building materials and it is also used in many different ways that go from construction to artistic creations. History tells us that the use of cementitious materials goes back to around 3000 B.C., when egiptians used gypsum and calcium to build the pyramids. Many centuries later, in 1824 Joseph Aspdin invented portland cement by burning a finely divided mixture of calcium and clay, the sinterized product was finely milled and was called portland cement because of the similar quality this mixture had compared to the building rocks found in Portland, England. ASTM defines portland cement as a hydraulic cement obtained by clinker milling, which essentially consists of hydraulic calcium silicates, and the addition of one or more forms of calcium sulfate.

Portland cement clinker is made of four ineralogical phases: Allite (Tricalcium Sulfate $\mathrm{C}_{3} \mathrm{~S}$ ), Bellite (Dicalcium Sulfate $\mathrm{C}_{2} \mathrm{~S}$ ), Tricalcium Aluminate $\left(\mathrm{C}_{3} \mathrm{~A}\right)$, and Tetracalcium Ferrialuminate $\left(\mathrm{C}_{4} \mathrm{AF}\right)$. White cement is produced by mixing calcium oxide, gypsum and kaolin.

One of the most important components in white cement production is kaolin. Kaolins are hydroaluminum-silicate of monoclinic or triclinic structure. Kaolins come from mineral alteration such as feldspar, granite, etc. during the tertiary and cretaceous environments 50 to 135 millions years ago.
Some of the major uses of kaolins are: paper products, ceramic tiles, paints, cement industry,etc. The lack of chromophores elements in kaolins is an essential factor in the white cement production. Some of the most common chromophores compounds are: $\mathrm{MgO}_{2}, \mathrm{Fe}_{2} \mathrm{O}_{3}$, $\mathrm{TiO}_{2}$, etc. The most significant goal of this research was to remove $\mathrm{Fe}_{2} \mathrm{O}_{3}$ from kaolins to meet the white cement standard levels of this compound $\left(\mathrm{Fe}_{2} \mathrm{O}_{3}\right.$ level should be less than $2 \%$ of the the total kaolin mass), the way $\mathrm{Fe}_{2} \mathrm{O}_{3}$ was removed from kaolins was possible by using a physical and chemical technique. Some other techniques used in other research projects are mentioned next: selective flocculation processes in which an aqueous mixture containing the minerals to be beneficiated is prepared and some acids are added to this mixture in order to get good flocculation, a very common acid utilized in this process is oleic acid [11, 12, 13,14]. Selective flocculation is used to separate a mixture of finely divided minerals into its constituents. When mineral particles are bigger than $45 \mu \mathrm{m}$ (US mesh 325), components in the mixture can also be separated by other physical means like air or magnetic separation. When mineral particles are smaller than $45 \mu \mathrm{m}$, the mineral separation is performed by the formation of an aqueous mixture containing the minerals to be beneficiated and adding chemicals which are responsible for the mineral separation.

A widely used process to separate phosphate or oxidized minerals with a silica matrix is froth flotation, it is conventional to use a fat acid collector and a salt promotor in this process. Mineral particles covered with the collector are separated from the matrix in the form of 
froth. Still another mineral beneficiation procedure, in particular for kaolins with titanium impurities is known as ultra flotation [17]. This process has been widely practiced over decades to improve the quality of kaolins, ultra flotation has even been used in the beneficiation of other comercial value minerals such as casiterite (tin oxide), fluorite, and other non sulphide minerals.

\section{Experimental Set up}

The tests and analysis were performed in the ceramic laboratories of the Faculty of Chemistry of the Universidad Autónoma de Nuevo León (U.A.N.L.), Center of Specialized Laboratories (U.A.N.L.), Graduate Laboratories of the Faculty of Electrical and Mechanical Engineering (U.A.N.L.), Hitachi Laboratories in the U.S.A.

\subsection{Materials and Equipment}

Four different kinds of kaolins were obtained from Villa de Reyes mineral pit on San Luis Potosí, México. The nomenclature of the four kaolins is as follows: L28, L30, L64 and L66.

The instruments used during this research were:

a) Ceramic ball mill

b) Meshes US $325(45 \mu \mathrm{m})$ and US $400(38 \mu \mathrm{m})$

c) X-ray diffractometer (Siemens D 5000)

d) Optical Microscope (Olympus Bx60 F5)

e) Scanning Electron Microscope (Hitachi S-2600H)

f) Colorimeter

g) Kilns and Press

h) General Lab Material and Computer Equipment

\subsection{Experimental Development}

\section{Mesh Grinding}

Each set of kaolins was milled the ceramic ball mill for one hour, after they were milled, kaolins went through mesh grinding using mesh number US 325 and US 400. Afterwards the material was classified as follows in accordance to their size from biggest to finest:
NM : Kaolins as they came from the mill

\section{R325: Material retained in mesh US 325}

R400 : Material that passed mesh US 325 or retained in mesh US 400

M400: Material that passed mesh US 400

\section{Chemical Washing}

To solubilize $\mathrm{Fe}_{2} \mathrm{O}_{3}$ present in kaolins, chemical treatments were performed using $\mathrm{HCl}$. Each kaolin was immersed in $20 \mathrm{ml}$ of $\mathrm{HCl}$ and heated to $80^{\circ} \mathrm{C}$ for 3 hours. After treatment with $\mathrm{HCl}$ and heat, kaolins were washed in water and were passed through filter paper, thus getting a clearer in color material. The chemical reaction between $\mathrm{Fe}_{2} \mathrm{O}_{3}$ and $\mathrm{HCl}$ is showed below :

$$
\mathrm{Fe}_{2} \mathrm{O}_{3}+6 \mathrm{HCl} \rightarrow 2 \mathrm{FeCl}_{3}+3 \mathrm{H}_{2} \mathrm{O}
$$

The remaining material in the filter paper are the washed clearer in color material.

\section{Ray Diffraction (XRD)}

After mesh grinding, XRD was performed on the four different kaolins and their classification in size from biggest to finest. The XRD analysis was performed using the following characteristics for analysis shown on Table $\mathrm{I}$ :

Table I. X Ray Diffraction Program

\begin{tabular}{|c|c|}
\hline Equipment & $\begin{array}{c}\text { Siemens D5000 } \\
\text { CuK } \alpha\end{array}$ \\
\hline Analysis Time & $56 \mathrm{~m} 40 \mathrm{~s}$ \\
\hline Step Time & $2.0 \mathrm{~s}$ \\
\hline Step Size & $0.050^{\circ}$ \\
\hline Start & $5^{\circ}$ \\
\hline End & $90^{\circ}$ \\
\hline Angular Speed & $15 \mathrm{RPM}$ \\
\hline Temperature & $\mathrm{Room}$ \\
\hline Tube Current & $25 \mathrm{~mA}$ \\
\hline Tube Voltage & $35 \mathrm{kV}$ \\
\hline
\end{tabular}




\section{Colorimetry}

A reflectance analysis was performed on the kaolins that had previously gone through mesh grinding, as well as the ones that went through chemical washing.

\section{Optical Microscopy}

Optical Microscopy analysis was performed on each of the kaolins that went through and were retained in meshes NM, R 325, R 400 and M 400. In order to be able to analyze kaolins in optical microscopy very thin samples of kaolins were gotten using a pressure of 2 metric tons during three minutes. Afterwards, the samples of material were mounted on bases made of a resin mixture. After cleaning up the bases in which the kaolins were embedded, optical analysis went on. Each kaolin sample went under the optical microscope at a $100 \mathrm{X}$ zoom and proceeded to take five micrographs of each sample for its later analysis using an image analyzer software with a discriminating color function. Given the fact that $\mathrm{Fe}_{2} \mathrm{O}_{3}$ is red in color, appropriate accounts of its presence were measured.

\section{Statistical Analysis}

A complete statistical analysis was performed on the measurements made by the image analyzer software about the size of the $\mathrm{Fe}_{2} \mathrm{O}_{3}$ particles found in the kaolin samples. This statistical analysis was made with the purpose of observing the variation, homogeneity, and size tendency of the $\mathrm{Fe}_{2} \mathrm{O}_{3}$ particles present in the different studied kaolins during the different stages of mesh grinding.

\section{Results}

\subsection{XRD}

XRD analysis for the four different kaolins are shown below, including the major phases present in each one of the kaolins as well as their evolution through meshes.

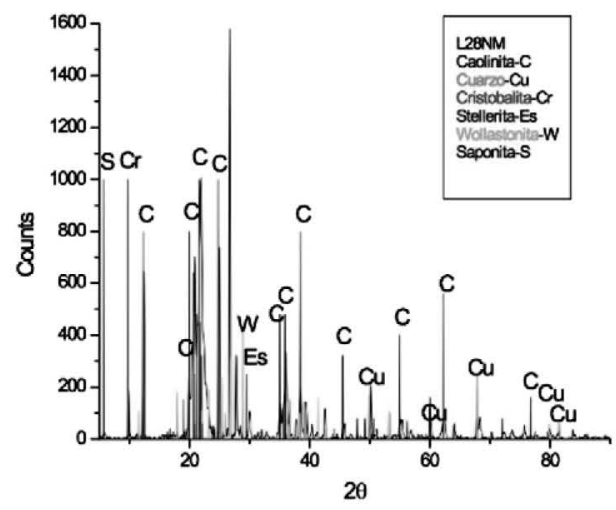

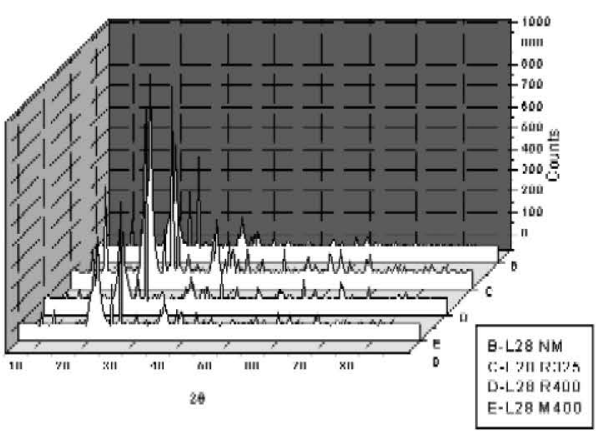

Fig.2. L 28 Mesh Evolution

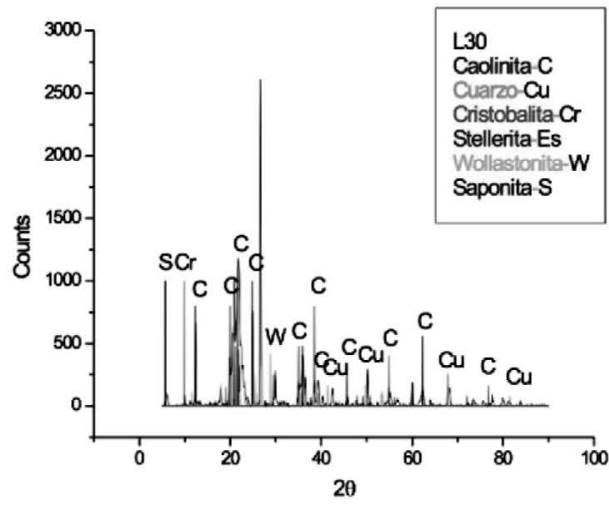

Fig.3. L 30 Spectra diffraction

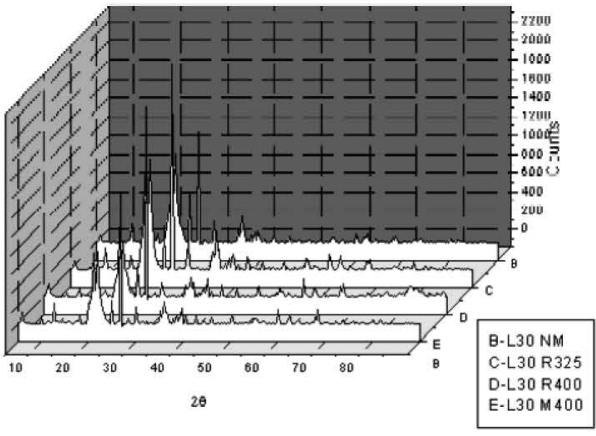

Fig.4. L 30 Mesh Evolution 


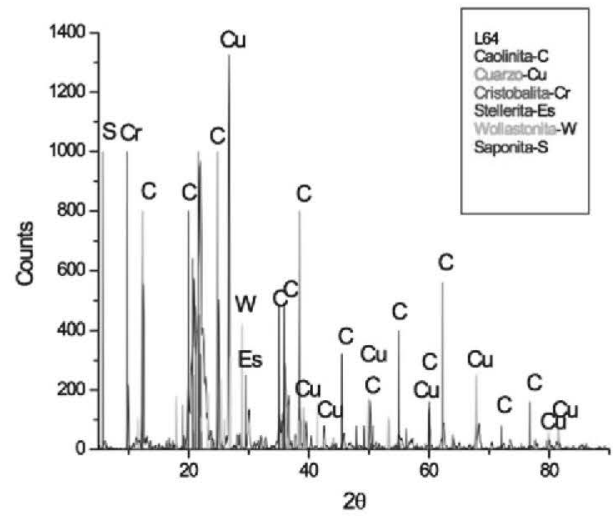

Fig.5. L 64 Spectra diffraction

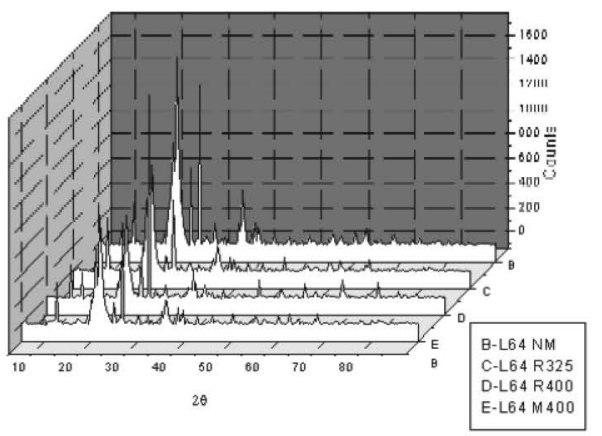

Fig. 6. L 64 Mesh Evolution

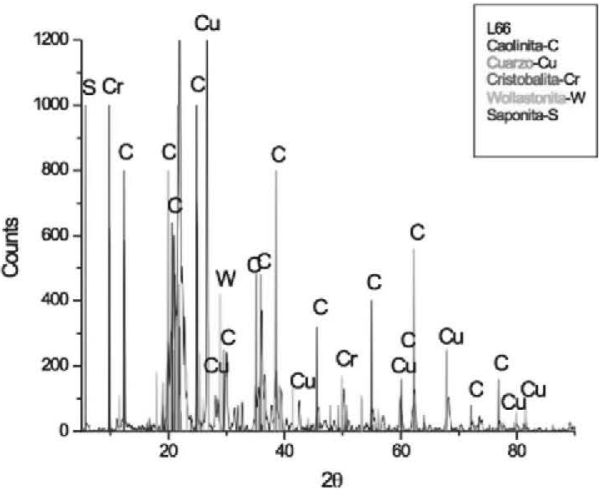

Fig.7. L 66 Spectra diffraction

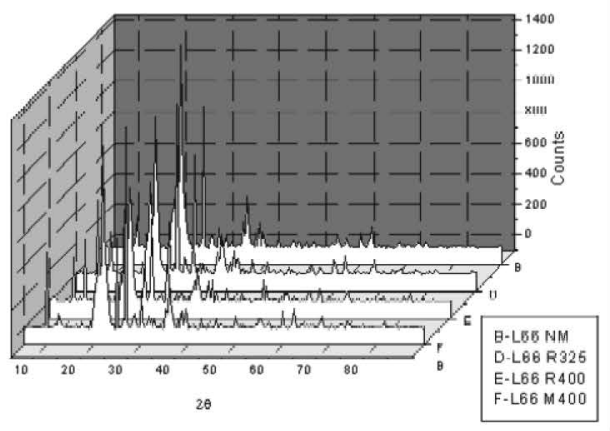

Fig.8. L 66 Mesh Evolution

On Table II are shown the probable locations of $\mathrm{Fe}_{2} \mathrm{O}_{3}$ in the different phases that compose the studied kaolins.

Table II. Probable location of $\mathrm{Fe}_{2} \mathrm{O}_{3}$

\begin{tabular}{|c|c|c|c|c|c|c|}
\hline & \multicolumn{6}{|c|}{ PHASE } \\
\hline Kaolin No. & Saponite & Stellerite & Kaolinite & Wollastonite & Quartz & Cristoballite \\
\hline 28 & & & $\mathrm{X}$ & $\mathrm{X}$ & & \\
\hline 30 & & & $\mathrm{X}$ & $\mathrm{X}$ & & $\mathrm{X}$ \\
\hline 64 & & & $\mathrm{X}$ & $\mathrm{X}$ & & $\mathrm{X}$ \\
\hline 66 & & & $\mathrm{X}$ & $\mathrm{X}$ & & \\
\hline
\end{tabular}

\subsection{Colorimetry}

The reflectance results for the different kaolins are shown below. 


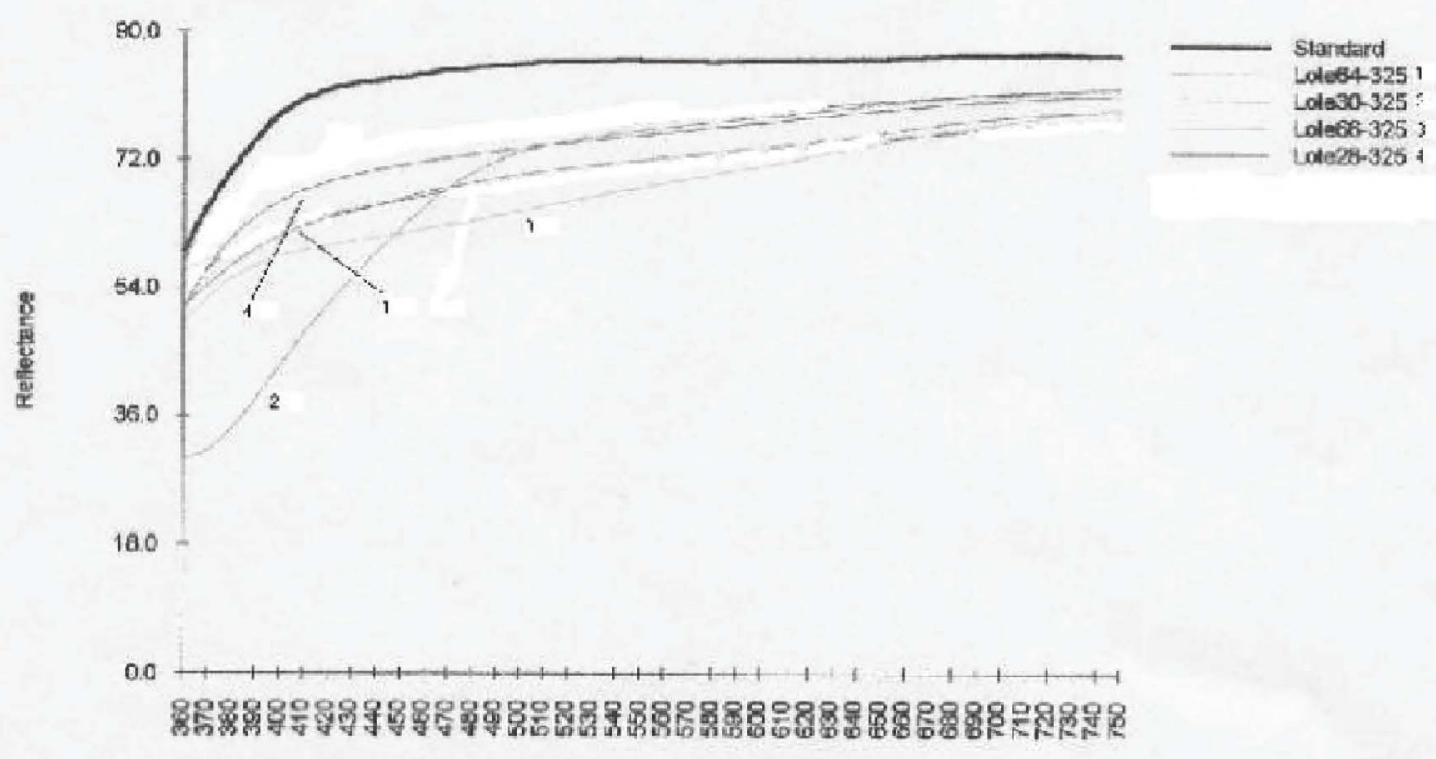

Wavelength (nm)

Fig.9. Colorimetry Analysis for mesh grinder kaolins

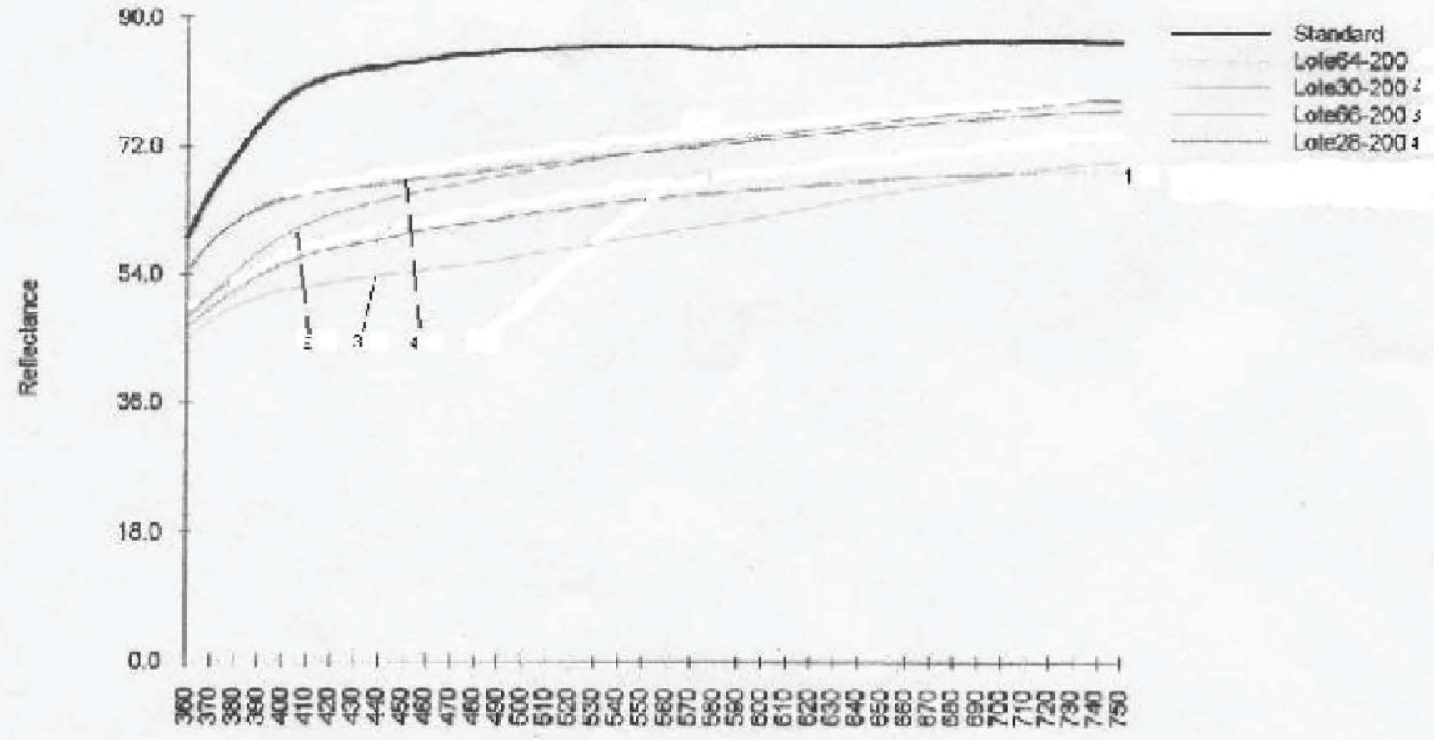

Wavelength (nm)

Fig. 10. Colorimetry Analysis for chemical washed kaolins

Under both treatments (mesh grinding and chemical washing) the studied kaolins show a similar beneficiation degree, that is, kaolins' reflectance tends to a clearer color.

\subsection{Optical Microscopy}

Below are a few of the most representative images of the optical microscopy analysis that kaolins underwent. 


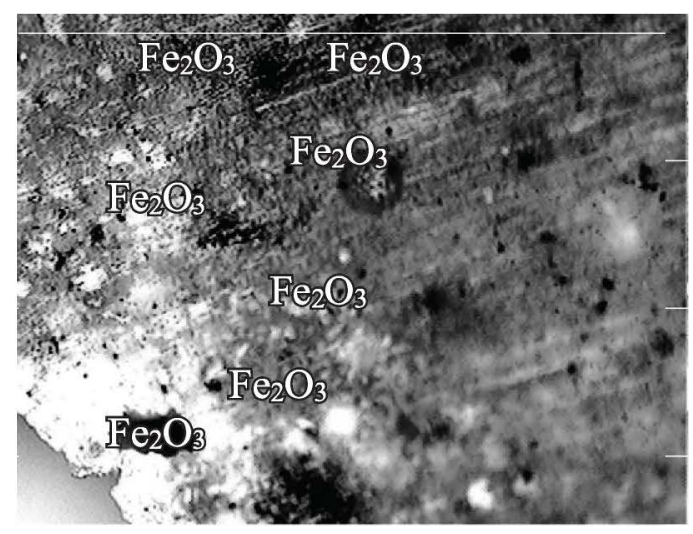

Fig.11. L 28NM

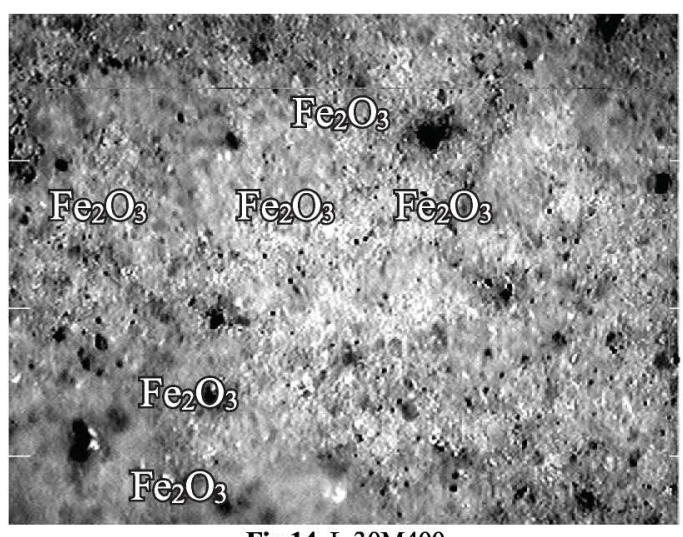

Fig 14. L 30M400

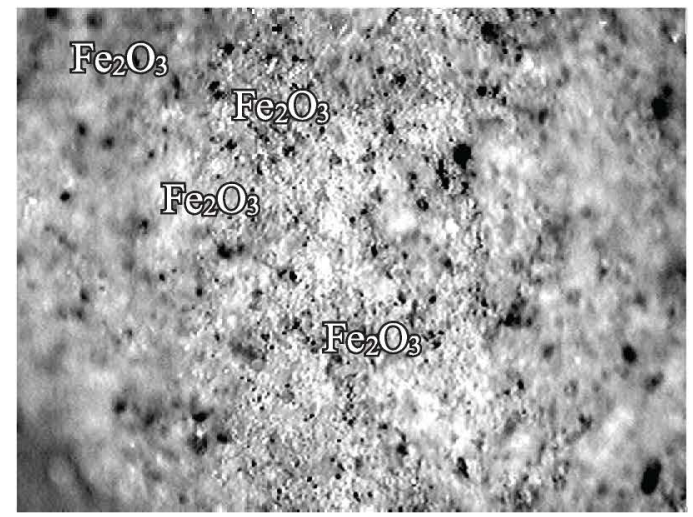

Fig. 12. L 28M400

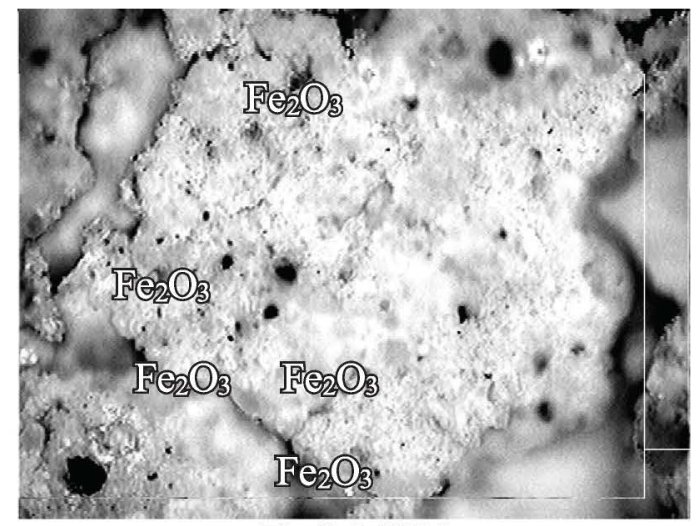

Fig. 13. L 30NM
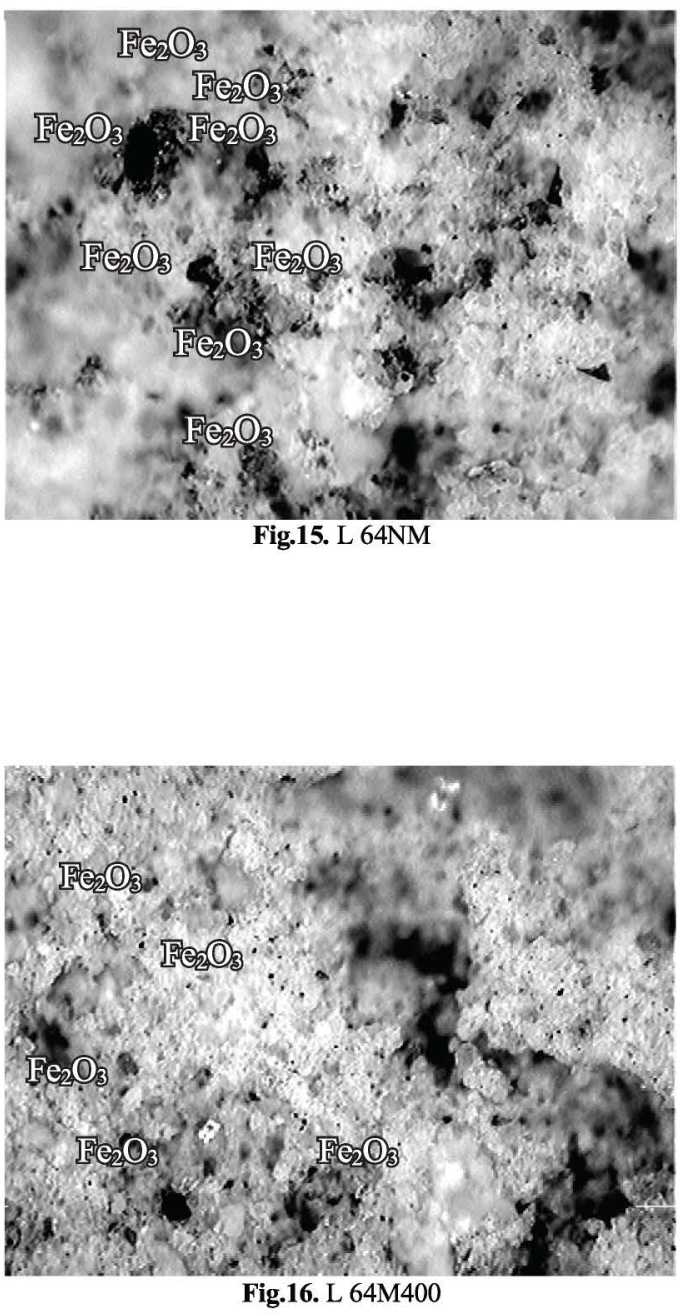


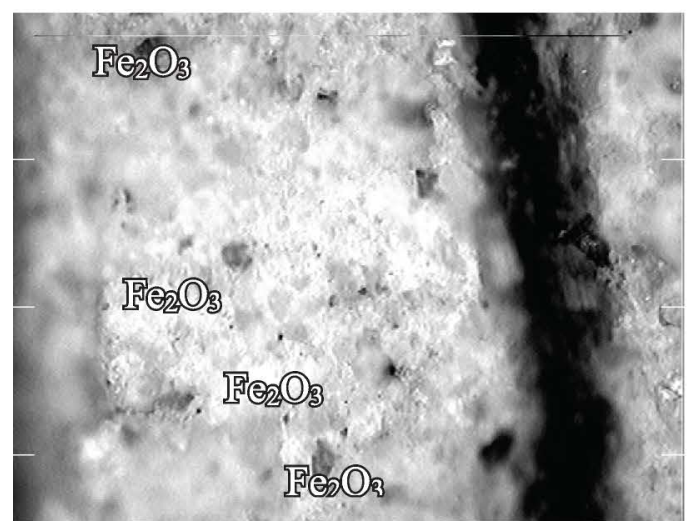

Fig.17. L 66NM

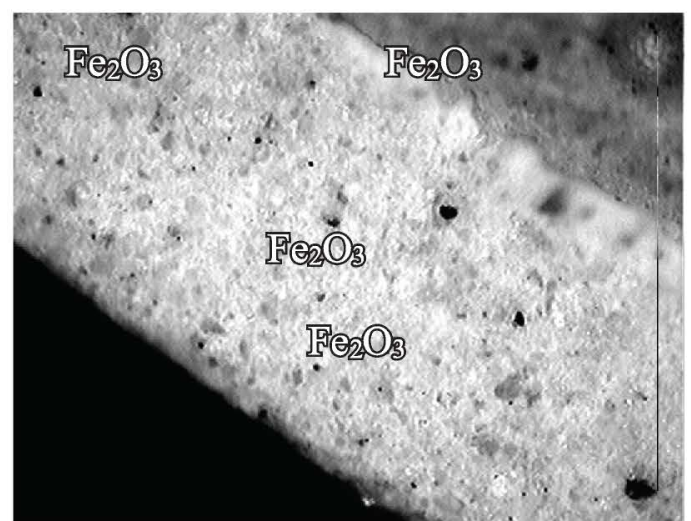

Fig.18. L 66M400

\subsection{Statistical Analysis}

The following graphs show $\mathrm{Fe}_{2} \mathrm{O}_{3}$ particle size evolution in the different studied kaolins. All the sizes shown are the average of the sizes measurements gotten by the five micrographs taken to each kaolin sample.

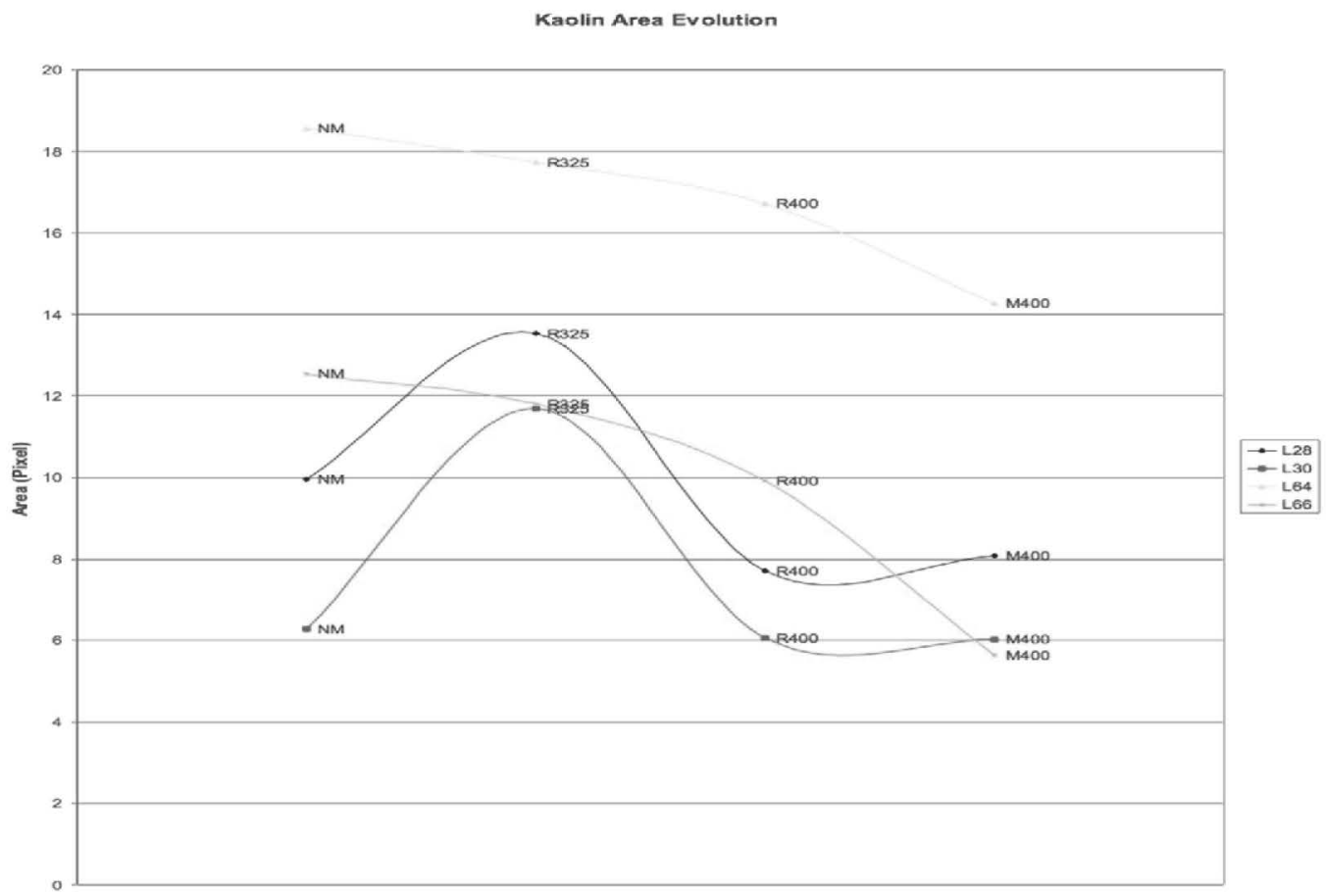

Fig. 19. Kaolins Area Evolution

\subsection{Scanning Electron Microscopy (SEM)}

SEM analysis was performed on kaolins as they were taken out the ceramic ball mill with the goal of studying their superficial features and microstructure. Some of the most representative images are shown below. 


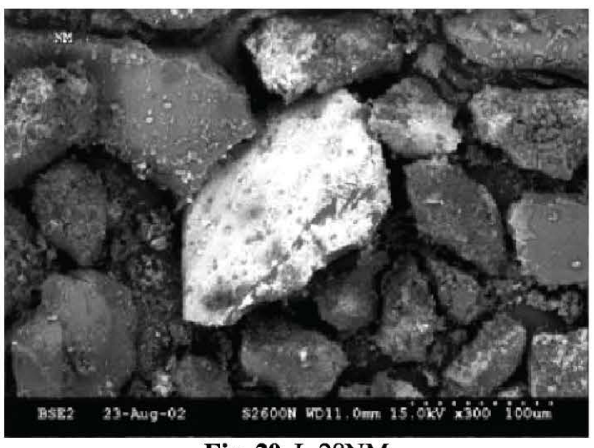

Fig. 20. L 28NM

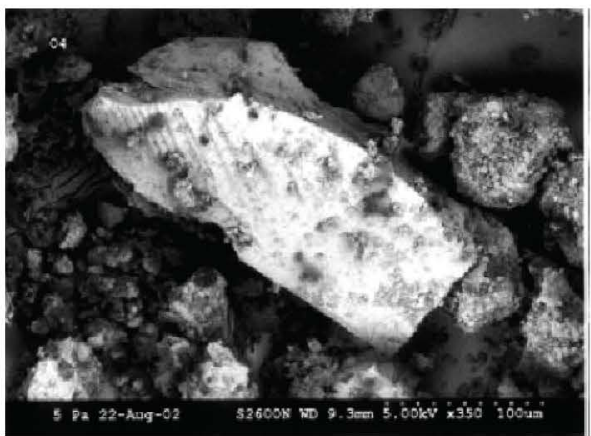

Fig. 21. L 28NM

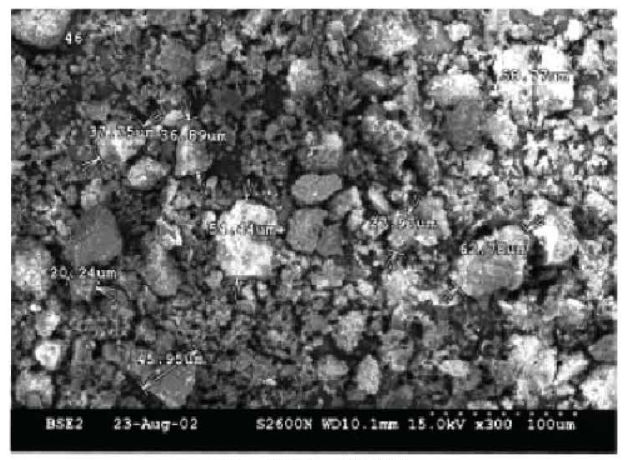

Fig. 22. L 30NM

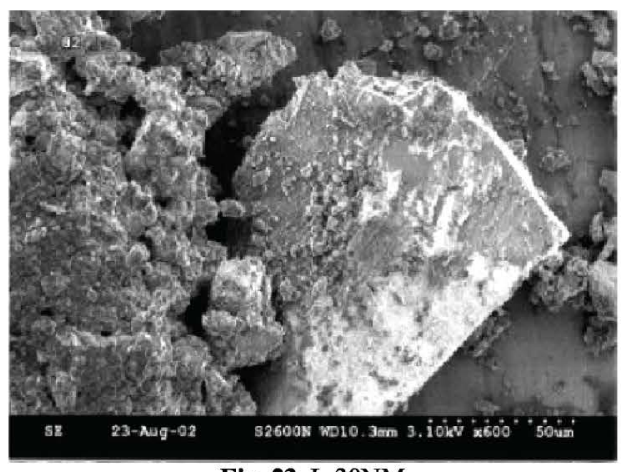

Fig. 23. L 30NM

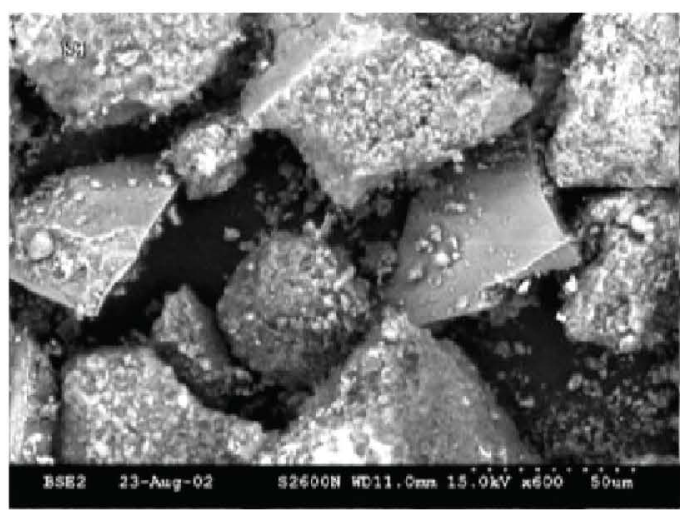

Fig. 24. L 64NM

\subsection{Elementary Mapping Analysis and EDAX}

Elementary Mapping Analysis was carried out in a sample of kaolin L 28NM, the images are shown below as well as an EDAX analysis practiced on the same sample.

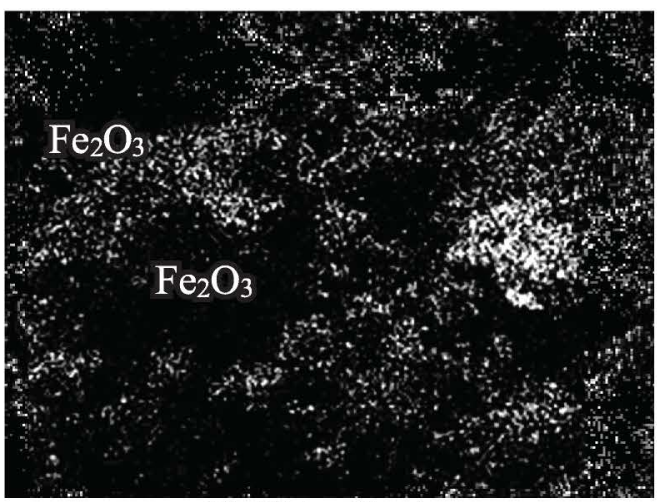

Fig. 25. Iron Mapping

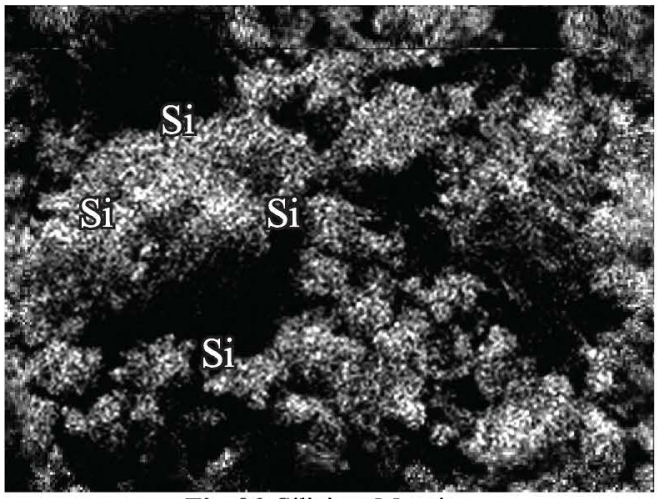

Fig. 26. Silicium Mapping 


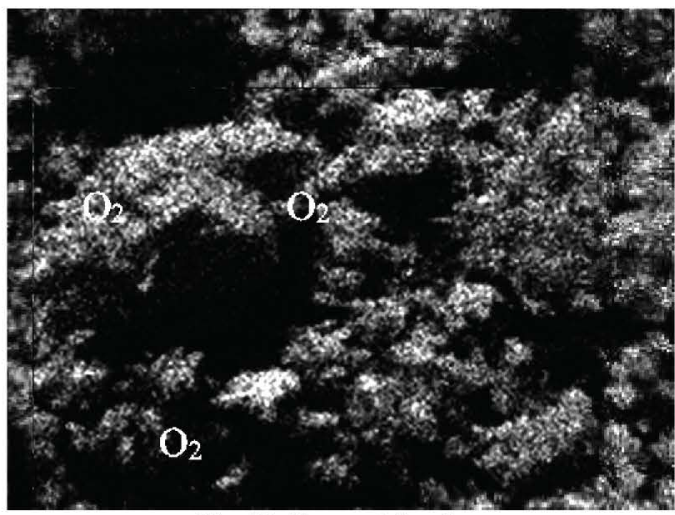

Fig. 27. Oxygen Mapping

- Sample 1 spectrum.ti 18: uoue

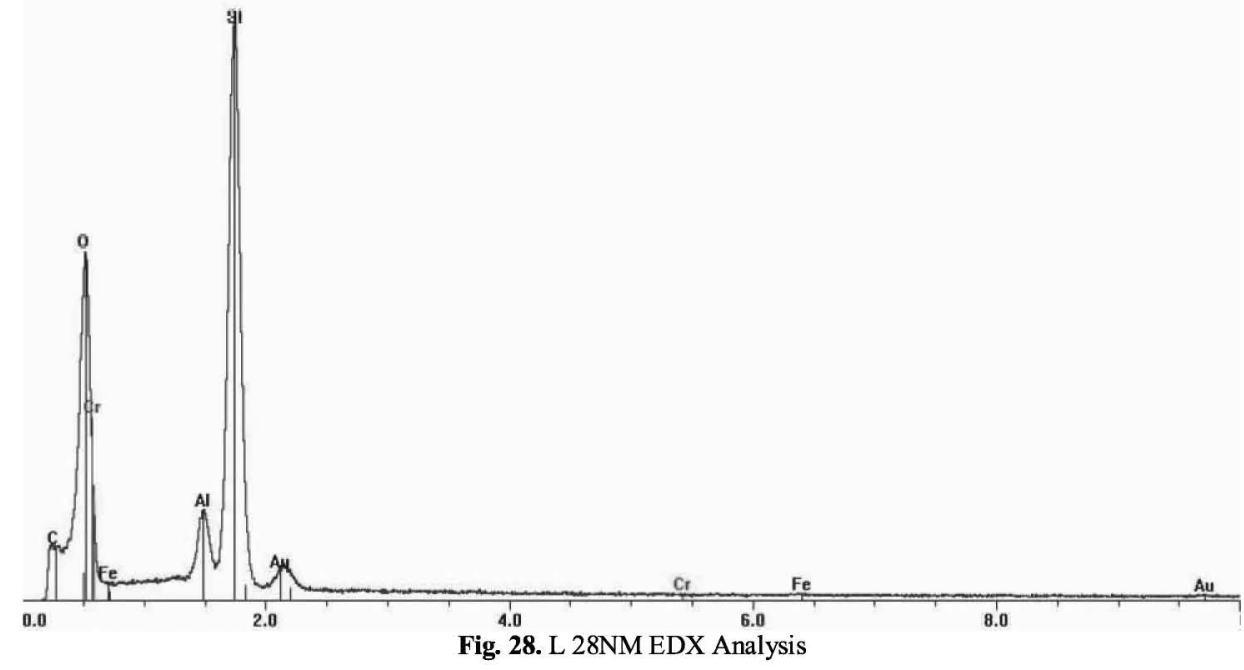

EDAX analysis shows the different elements found on $\mathrm{L} 28 \mathrm{NM}$ and are: $\mathrm{Si}, \mathrm{Fe}, \mathrm{O}, \mathrm{Cr}$ and $\mathrm{Al}$.

\section{Results Analysis}

\section{1 $\mathrm{Fe}_{2} \mathrm{O}_{3}$ location in kaolin's phases}

The probable location $\mathrm{Fe}_{2} \mathrm{O}_{3}$ in the indicated kaolin phases on table $I I$ is obtained under the combined analysis of XRD patterns as they go through the different mesh numbers, as well as the optical microscopy technique and its statistical analysis. It could be seen on the XRD patterns that certain kaolin phases diminish in intensity such as quartz, kaolinite and wollastonite when they advance in mesh number, after that, those same phases increase their intensity, all of this with respect to the original intensity shown on each of the kaolins that still hadn't gone through any mesh, i.e NM. When analyzing optical micrographs, it could be seen that when the mesh number got higher, kaolin's color changes from dark red on NM kaolins, up to much clearer colors on M
The Elementary Mapping Analysis indicates that silica is the most abundant element in the kaolin sample, followed by oxygen and lastly iron. These images also show that iron and oxygen combine, thus forming $\mathrm{Fe}_{2} \mathrm{O}_{3}$ , there's also the combination of silica and oxygen as expected and confirmed by the different kinds of analysis practiced on the studied kaolins.
400 kaolins. It can also be observed in these micrographs that $\mathrm{Fe}_{2} \mathrm{O}_{3}$ particle size diminishes when the mesh number rises, and also the particle's general distribution becomes more uniform. These particle size observations are also confirmed through the $\mathrm{Fe}_{2} \mathrm{O}_{3}$ statistical analysis. With all of these observations the probable location of $\mathrm{Fe}_{2} \mathrm{O}_{3}$ can be discerned.

These analyses indicate that $\mathrm{Fe}_{2} \mathrm{O}_{3}$ particles are being retained in the greater size meshes and their size is becoming smaller as expected, thus obtaining a clearer color on kaolins. On XRD analysis it can be observed that kaolinite, quartz and wollastonite diminish in intensity as previously stated, as well as the kaolin's coloration becomes clearer, it is also observed at this point that the average particle size increases. Later, a clearer coloration is observed and that those same phases (kaolinite, quartz, and wollastonite) now increase in intensity, and the $\mathrm{Fe}_{2} \mathrm{O}_{3}$ particle size diminishes. Lastly, in the last mesh number (400), it is seen in all of the cases an even clearer coloration and the mentioned phases 
increase even more in intensity (kaolinite and quartz), and in some cases the intensity increases on an exponential manner (kaolinite) and the $\mathrm{Fe}_{2} \mathrm{O}_{3}$ particle size becomes smaller and more uniform. All of these observations give us the $\mathrm{Fe}_{2} \mathrm{O}_{3}$ probable location in the different kaolin phases.

\subsection{Colorimetry}

Maxwell's equations predict the existence of electromagnetic waves whose speed in vacuum is determined by:

$\mathrm{C}=\left(\mu_{0} \varepsilon_{0}\right)^{-1 / 2}$

where $\mathrm{c}$ is the speed of light or the speed of electromagnetic waves, $\mu_{0}:$ space permeability, $\varepsilon_{0}$ : permittivity constant. From Maxwell equations it can be concluded that all of these electromagnetic waves have the same nature and differ only in their frequency and wavelength. When a colorimetry analysis is performed, it is only limited to avery narrow region of the electromagnetic spectrum called visible region. Results gotten using colorimetry show a graph of reflectance versus wavelength, that is, reflectance versus color. This means that the major reflectance percentage indicates the most predominant color in the analyzed sample. In the present research similar results were obtained for kaolins that went through chemical treatment as well as for kaolins that went through mesh grinding, in both cases showing a similar beneficiation degree, i.e. the same wavelength range was predominant for both beneficiation techniques.

\subsection{Statistical Analysis}

Statistical analysis performed on the micrographs obtained by optical microscopy was done with the purpose of observing $\mathrm{Fe}_{2} \mathrm{O}_{3}$ particle size variations. This was possible by using an image software analyzer with a color discrimination function. Because of the fact that optical microscopy analysis allows the obtention of measurements of $\mathrm{Fe}_{2} \mathrm{O}_{3}$ particle size, these measurements are done on the basis of the different optical phenomena that the light beam focusing on the kaolin sample produces. The measurement of $\mathrm{Fe}_{2} \mathrm{O}_{3}$ particle size is a function of an area whose mathematical algorithm is of fractal dimension [18].

Five micrographs of each kaolin sample that went through the different mesh numbers were taken to measure the average area of $\mathrm{Fe}_{2} \mathrm{O}_{3}$ particles. The $\mathrm{Fe}_{2} \mathrm{O}_{3}$ particle size graphs shows that the average area of $\mathrm{Fe}_{2} \mathrm{O}_{3}$ particles rises and then diminishes as the mesh number increases in two of the studied kaolins (L 28, L 20), and in the other two kaolins ( $\mathrm{L} \mathrm{64,} \mathrm{L}$ 66) the average $\mathrm{Fe}_{2} \mathrm{O}_{3}$ particle size simply decreases as the mesh number increases. These results indicate us that $\mathrm{Fe}_{2} \mathrm{O}_{3}$ particles are being retained in US 325 mesh in two of the studied kaolins (L 28, L 30), and on kaolins $\mathrm{L} 64$ and $\mathrm{L} 66 \mathrm{Fe}_{2} \mathrm{O}_{3}$ particles are being retained in more less uniform quantities as these kaolins advance in mesh numbers.

In mesh US 400 the $\mathrm{Fe}_{2} \mathrm{O}_{3}$ particle size becomes smaller and more homogeneous in its distribution in three of the studied kaolins (L 28, L 30, and L 64) and in L 66 a lesser degree of homogeneity in $\mathrm{Fe}_{2} \mathrm{O}_{3}$ particle size distribution is observed.

\subsection{SEM, Elementary Mapping and EDX}

SEM analysis show similar morphologies in all the studied kaolins. It is observed that $\mathrm{Fe}_{2} \mathrm{O}_{3}$ particles are outside of the kaolin structure as was expected because of the beneficiation results gotten by physical means. Particles' morphologies went from polygonal, polyhedral up to irregular in shape. Particles' distribution went from uniform up to totally random. Particles' polygonal shapes correspond to clays as reported in literature. Particle irregular shapes correspond to different oxides and silica combinations, some polygonal shapes belong to $\mathrm{Fe}_{2} \mathrm{O}_{3}$ found on the kaolin samples. $\mathrm{Fe}_{2} \mathrm{O}_{3}$ was identified on the SEM micrographs due to the contrast shown on the images, being much brighter than the rest of the other structures on the samples, as well as because of its morphology and its corresponding elementary mapping.

Discreet element mapping shows that the most abundant element is silica, followed by oxygen and lastly iron as mentioned before. By studying these elementary mappings, the following can be concluded:

a) Iron combines with oxygen, not with silica which corroborates the optical microscopy analysis.

b) Silica combines with oxygen, which does not differs from what was found in XRD and optical microscopy analysis and this is particularly relevant because it means that the studied kaolins come from a recent geological age meaning that their $\mathrm{SiO}_{2}$ content is particularly high and that these kaolins are from the feldspar type. This situation should be taken into count if these kaolins are to be used in the white cement industry.

EDX analysis shows five different basic elements that are: silica, oxygen, chrome, aluminium, and iron, as well 
as showing gold and carbon that come from the sample preparation and sample fixing respectively. The most abundant elements were silica and oxygen. Chrome and iron are natural pollutants found in some clays.

\section{Conclusions}

a) XRD analysis show the same six most abundant phases on the four studied kaolins, and these are: saponite, kaolinite, wollastonite, stellerite, crystoballite and quartz.

b) Intensity of phases in XRD analysis varied as the number of mesh changed.

c) Mesh grinding and chemical washing techniques applied on the studied kaolins show a similar behavior or tendency, that is, the wavelength of the maximum reflectance of the studied kaolins tends to be that of the white color, this means that under both treatments (mesh grinding and chemical washing) kaolins show a similar beneficiation degree.

d) $\mathrm{Fe}_{2} \mathrm{O}_{3}$ particle size measurements the following is concluded:

$>\mathrm{Fe}_{2} \mathrm{O}_{3}$ particles' sizes become more homogeneous as the mesh number increases.

$>\mathrm{Fe}_{2} \mathrm{O}_{3}$ particles' morphology become more circular or punctual as mesh numbers went higher.

$>\mathrm{Fe}_{2} \mathrm{O}_{3}$ particles' color vary from dark red to a much clearer color as the mesh number increases.

e) Probable $\mathrm{Fe}_{2} \mathrm{O}_{3}$ particles' location in the kaolins' structure are: kaolinite, wollastonite, and crystoballite.

f) SEM, discreet mapping and EDX analysis show the following:

$>$ A similar structure for all the studied kaolins was observed.

$>\mathrm{Fe}_{2} \mathrm{O}_{3}$ particles are outside of the main kaolin structure.

> Structures made up of a combination of silica and oxygen are polygonal in shape as reported in literature.
$>$ The most abundant element is silica, followed by oxygen and lastly iron.

$>$ Oxygen combines with iron and silicium as expected and also corroborated by optical microscopy analysis. Combinations of silicium and iron were not found.

$>$ EDX analysis show five different kaolin's components: silicium, oxygen, aluminium, iron and chrome.

\section{References}

1. Borchardt-Ott, W. Crystallography, $2^{\text {nd }}$ ed.; Springer: 1995

2. Taylor, H. F. W.; Brunauer, Stephen, $L a$ química de los cementos, $1^{\text {ts }}$ ed.; Bilbao: Urmo, 1967

3. Zehany Wang, Study on the Process for Puryfying Naturally Ocurring Silice to High Purity Quartz Powder._September, 1997

4. Campos A. R.; Chaves A. P. Technological Aspects on the Beneficiation of Candiota Coal._September, 1997

5. P.N. Deo, K.S. Raju, Processing of Indian Kaolin Clays,_September, 1997

6. Organismo Nacional de Normalización y Certificación de la Construcción y Edificación, S.C. Norma Mexicana NMX-CONNCCE-1999. Industria de la Construcción Cementos Hidráulicos - Especificaciones y Métodos de Prueba.

7. Pickering, Jr. et al., Process for Whitening Kaolin, U.S. Patent: 5,545,599. August, 1996

8. Shi, et al., Process for Removing Impurities from Kaolin Clays, U.S. Patent: 5,522,986. June, 1996

9. El-Shall; Dewatering Method and Agent,_U.S. Patent: 5,449,464. September, 1995

10. Norris, et al., Kaolin Clays which are Conditioned prior to Removing Impurities U.S. Patent: 6,007,618. December, 1999

11. Behl, et al., Method for Separating Mixture of Finely Divided Minerals U.S. Patent: 5,535,890. July, 1996

12. Behl, et al., Colored Titanoferous Coating Pigment Obtained as a Flocculated ByProduct in a Kaolin Purification Process U.S. Patent: 5,688,315. November, 1997 
13. Williams, et al., Method for Separating Mixture of Finely Divided Minerals U.S. Patent: 5,603,411. February, 1997

14. Behl, et al., Colored Titanoferous Coating Pigment Obtained as a Flocculated ByProduct in a Kaolin Purification Process U.S. Patent: 5,584,394. December, 1996

15. Norris, et al., Process for Conditioning Kaolin Clays Prior to Removing Impurities U.S. Patent: 5,685,899. November, 1997

16. Shi, et al., Process for Removing Impurities from Kaolin Clays U.S. Patent: 5,891,326. April, 1999

17. Green et al., Use of Ultraflotation in Kaolinitic Clays U.S. Patent: 2,990,958. May, 1998 